\title{
América Latina y la Unión Europea: agendas sociales, competencia geopolítica y COVID-19
}

\section{Latin America and the European Union: Social Agendas, Geopolitical Contest, and COVID-19}

\author{
José Antonio Sanahuja ${ }^{1}$ \\ Fundación Carolina, Madrid (España)
}

Recibido: 01-08-20

Aceptado: 04-09-20

\section{Resumen}

La Unión Europea y América Latina y el Caribe cuentan con un importante acervo de relaciones políticas y económicas, a través de una red de Acuerdos de Asociación que ha sido el objetivo de la estrategia interregional desplegada desde los años noventa. Un escenario de crisis de globalización y contestación del sistema multilateral, al que se suma la crisis de la COVID-19, somete esas relaciones a nuevas tensiones. Este artículo examina el estado actual de la "Asociación estratégica birregional" y plantea posibles bases para su renovación frente a un escenario de creciente competencia geopolítica. Se argumenta que para ser relevante la UE debe promover una agenda centrada en las prioridades de las sociedades de ambas regiones guiada por la Agenda 2030 de Desarrollo Sostenible y el European Green Deal, frente a la competencia geopolítica y a las políticas de poder de grandes potencias como Estados Unidos y China.

Palabras-clave: Unión Europea, América Latina y el Caribe, desarrollo sostenible, cooperación.

\footnotetext{
${ }^{1}$ (sanahuja@cps.ucm.es). Catedrático de Relaciones Internacionales de la Universidad Complutense y profesor de la Escuela Diplomática. Director de la Fundación Carolina y asesor especial para América Latina y el Caribe del alto representante para la política exterior y de seguridad de la Unión Europea (ad honorem). Ha sido investigador del Instituto Complutense de Estudios Internacionales (ICEI) y Robert Schuman Fellow del Instituto Universitario Europeo de Florencia. Entre sus trabajos se encuentran La Agenda 2030 en Iberoamérica. Políticas de cooperación y "desarrollo en transición” (ed., 2020); Teorias de las Relaciones Internacionales (coord., con C. Arenal, 2015); y América Latina y los Bicentenarios. (ed., con T. Mallo, 2010).

ORCID: https://orcid.org/0000-0002-6806-5498.
} 


\begin{abstract}
The European Union and Latin America and the Caribbean have an important acquis of political and economic relations, through a network of Association Agreements that has been the goal of the interregional strategy deployed since the 1990s. A scenario of crisis of globalization and contestation of the multilateral system, as well as the crisis of COVID-19, put these relations into new strains. This article examines the current state of the "Bi-regional Strategic Association" and raises possible bases for its renewal in the face of a scenario of increasing geopolitical competition. It is argued that to be relevant, the EU must promote an agenda focused on the priorities of the societies of both regions guided by the 2030 Agenda for Sustainable Development and the European Green Deal, in the face of geopolitical competition and power policies of great powers like the United States and China.
\end{abstract}

Key-words: European Union, Latin America and the Caribbean, Sustainable Development, Cooperation.

\title{
Introducción:
}

Más de cuatro décadas de diálogo político, relaciones económicas y cooperación al desarrollo han tejido importantes interdependencias y conexiones entre la Unión Europea y América Latina y el Caribe. Aunque su significación es objeto de contestación y disputa, existe una trayectoria histórica compartida y una vinculación sociocultural única cuando se contempla el conjunto de las relaciones exteriores de ambas regiones. Finalmente, existe un importante núcleo de principios y valores que ambas regiones comparten, con todos sus matices y diferencias de grado, en cuanto a inclusión y democracia social y un importante consenso sobre las reglas básicas que deben regir el sistema internacional.

La frecuente $\mathrm{y}$ en ocasiones ritual invocación de ese acervo de interdependencias materiales, instituciones y consensos normativos, no supone ignorar las asimetrías de poder y riqueza que siguen vigentes y que ese patrón de relaciones tiende a reproducir; tampoco debe servir de coartada para eludir cuestiones clave para su análisis, referidas a las estrategias, los actores y la forma en la que responden o no a los cambios en la estructura del sistema internacional.

Este artículo trata ofrecer una mirada de conjunto a las relaciones entre ambas regiones atendiendo tanto a los resultados de la estrategia interregionalista adoptada por la Unión Europea desde mediados de los noventa, como a los retos que enfrenta la relación birregional. Se analizarán, en particular, las dificultades que enfrentaba esa estrategia en un escenario internacional en cambio y los 
desafíos que ha planteado la crisis de la COVID-19. Esta pandemia ya es, por un lado, una crisis de desarrollo, y no sólo una crisis sanitaria. Y, por otra parte, esa crisis se produce dentro de otra crisis más amplia, la que afecta a la globalización, y es esa crisis de globalización, más que el patógeno y sus características, la que explica en buena medida el impacto y efectos económicos, sociales y políticos de la pandemia (Sanahuja 2020b). A partir de ese análisis se plantea, desde la perspectiva de la UE, qué elementos pueden contribuir a la renovación de la relación birregional y qué retos enfrenta.

\section{El acervo histórico: diálogo político, relaciones económicas, cooper- ación al desarrollo}

En 2019 se cumplieron veinte años de la I Cumbre UE-América Latina y el Caribe (Río de Janeiro, 28 y 29 de junio 1999), si bien el diálogo político institucionalizado entre ambas regiones tenía una trayectoria mucho más larga: en 1974 se inició el diálogo interparlamentario entre ambas regiones, impulsado por las internacionales políticas del momento en respuesta a las dictaduras militares y los "regímenes de seguridad nacional". En los años ochenta, con el inicio de la democratización de la región, se estableció un diálogo político entre gobiernos para respaldar el proceso de paz en Centroamérica, y las transiciones y consolidación de la democracia. En los años noventa, en el nuevo escenario de la posguerra fría, la Comisión Delors, con el liderazgo del entonces vicepresidente Manuel Marín, adoptó una nueva estrategia "interregional" en el marco de la recién estrenada Política Exterior y de Seguridad Común (PESC) establecida por el Tratado de Maastricht. En ese marco, la Cumbre de Río de 1999 estableció una "asociación estratégica birregional" con tres pilares: diálogo político de alto nivel (cumbres de Jefes de Estado y de Gobierno), fomento del comercio y las inversiones a través de "Acuerdos de Asociación" y una cooperación al desarrollo muy avanzada (Domínguez, 2015; Sanahuja, 2015).

En cuanto al diálogo político, el saldo general es positivo. Veinte años después de la Cumbre de Río, las relaciones se han intensificado y se han celebrado siete cumbres de jefes y jefas de Estado y de Gobierno. En las dos últimas, en Santiago de Chile (2013) y Bruselas (2015), la parte latinoamericana actuó a través del propio mecanismo de concertación regional, la Comunidad de Estados Latinoamericanos y Caribeños (CELAC). Estas cumbres, que involucran a 61 países (una tercera parte de la comunidad internacional), han reafirmado los valores compartidos, los propios del orden internacional liberal (democracia, derechos humanos, Estado de derecho, sociedades abiertas, apertura económica y respaldo al multilateralismo), aunque con acentos 
propios (cohesión social y apoyo al regionalismo y la integración regional). Con Brasil y México, además, se ha establecido un marco adicional de diálogo político y cooperación, denominado "asociación estratégica", para singularizar la importancia de estos dos países de la región. En paralelo, existen diálogos políticos estructurados sobre migraciones o lucha contra las drogas ilícitas, y ha habido una intensa actividad de diálogos subregionales, de la sociedad civil, e interparlamentarios, a través de la Asamblea EuroLat, creada en 2006 y vinculada orgánicamente al Parlamento Europeo.

Desde mediados de los noventa se promovió la creación de una red de "Acuerdos de Asociación" acorde a la renovada cartografía de la integración regional de América Latina y el Caribe bajo los parámetros del llamado "regionalismo abierto". Esos acuerdos incluyen esos tres pilares: diálogo político, libre comercio y cooperación. En 2020, esa red está cercana a cerrarse: incluye 31 de los 33 países que integran la región. Hay acuerdos con México, Chile, Perú, Colombia, Ecuador, Centroamérica, Panamá, el Caribe y el Mercosur, este último, pendiente de ratificación tras veinte años de difíciles negociaciones, más un acuerdo de diálogo político y cooperación con Cuba. Solamente Venezuela y Bolivia - esta última, en proceso de ingreso a Mercosurcarecen de acuerdos con la UE (Tvevad, 2020). Además, se está negociando la modernización del acuerdo con Chile, y en 2020 se ha culminado la renovación del vigente con México (Domínguez, 2020).

En el ámbito comercial, la UE es el tercer socio comercial más importante de América Latina y el Caribe, por detrás de Estados Unidos $\left(1^{\circ}\right)$ y China $\left(2^{\circ}\right)$. En sentido contrario, la región ocupa, en agregado, el quinto lugar entre los principales socios comerciales de la UE. En los últimos diez años el comercio birregional ha crecido un 22\% (de 185.000 millones de euros en 2008 a 225.400 millones en 2018). Buena parte de esos flujos, y en aumento, es comercio de servicios (102.000 millones de euros) (Grieger, 2019).

La UE es, además, la principal fuente de inversión extranjera directa (IED) en América Latina y el Caribe, en monto y calidad, con un crecimiento del 210\% entre 2007 (stock de 253.100 millones de euros) y 2017 (784.600 millones de euros). En sentido opuesto, la IED de América Latina y el Caribe en la UE aún es reducida, aunque ha crecido 266\% entre 2007 (74.600 millones de euros) y 2017 (273.000 millones de euros). Respecto a la IED de China y Estados Unidos (más presente en sectores extractivos e infraestructura), la IED europea tiene más calidad: se caracteriza por estándares laborales, sociales y ambientales más elevados, y una mayor transferencia de tecnología, y tiene el liderazgo en industria y servicios y en sectores clave para la Agenda 2030 de Desarrollo Sostenible (p. ej. energías renovables y conservación del medio ambiente). 
Finalmente, la UE (instituciones de la Unión junto con los Estados miembros) es el mayor donante en la cooperación al desarrollo con América Latina en términos absolutos. Como UE, en el periodo presupuestario y de programación 2014-2020 se destinaron 3.600 millones de euros a programas bilaterales y regionales, enfocados a áreas como seguridad y Estado de derecho; sostenibilidad ambiental y combate al cambio climático; agricultura, alimentación y seguridad alimentaria; crecimiento económico incluyente para la generación de empleos y reforma de la administración pública. La UE es además particularmente activa en áreas donde otros donantes apenas inciden, como el diálogo y aprendizaje conjunto de políticas climáticas (Euroclima), sobre cohesión social (Eurosocial), la construcción de la paz (Colombia), la defensa de los derechos humanos y el fortalecimiento de la sociedad civil, y el apoyo a la integración regional. La región también recibe aportes de ayuda humanitaria en situaciones de emergencia, y en algunas, como los incendios forestales en Chile, se han desplegado medios del Mecanismo Europeo de Protección Civil. El Banco Europeo de Inversiones (BEI) cuenta con líneas de crédito para la región en diversos sectores productivos, particularmente en el freno y adaptación al cambio climático (3.400 millones de euros entre 2014 y 2018). A través de operaciones de financiación combinada o blending, entre 2010 y 2019 la Comisión Europea ha logrado movilizar préstamos en áreas prioritarias de desarrollo de la región por algo más de 10.000 millones de euros. Finalmente, ambas regiones son importantes socios en la cooperación en ciencia y tecnología, a través de la participación de centros de investigación de la región en los programas marco de la UE y en "Horizonte 2020", con marcos de programación bilaterales con los principales países de la región (Sanahuja y Ruíz, 2019) y a través de algunos países de la región en la red satelital Copernicus de la Agencia Espacial Europea.

En suma, si se adopta una visión de largo plazo, las relaciones birregionales cuentan con un valioso acervo acumulado, y son un referente importante de las relaciones exteriores de los países involucrados, tanto en lo referido a sus intereses, como a sus valores y su identidad internacional. No obstante, como se indicó, esas relaciones se han ido enfrentando en los últimos años a un escenario internacional transformado, en muchos aspectos más adverso, y a crecientes tensiones al interior de cada grupo que son parte de una dinámica más amplia de cuestionamiento del regionalismo y la integración regional. Todos esos elementos interpelan su racionalidad y objetivos, y ponen en cuestión su viabilidad. 


\section{Relaciones en tensión ante un escenario internacional adverso}

En gran medida, en esos veinte años las relaciones entre la UE y América Latina y el Caribe han respondido a una estrategia interregionalista, funcional a un patrón de globalización fuertemente regionalizada, que sustentó una particular forma de internacionalismo liberal como orden internacional hegemónico. Desde 2008, sin embargo, el sistema internacional inicia una etapa de crisis de la globalización y del orden internacional liberal que ha puesto en cuestión dicha estrategia y la somete a crecientes tensiones. Esa crisis de globalización ha estado impulsada tanto por factores de estructura como de agencia. Entre los primeros, cabe mencionar el cambio social y de expectativas generado por la globalización, que es un factor explicativo de las tendencias a la desafección democrática que, en distinto grado, se observan en ambas regiones. También pueden mencionarse los cambios tecnológicos, que anuncian una nueva organización internacional de la producción y están dando lugar a fuertes costes de ajuste en los mercados de trabajo y a mayor incertidumbre y desajustes en materia de empleo y cohesión social. Entre los factores de agencia, el ascenso de fuerzas políticas nacionalistas, "iliberales" y de extrema derecha que se nutren del mayor descontento social, el cuestionamiento del multilateralismo y el regionalismo por parte de esos actores políticos, y la posición revisionista de los países emergentes, que en conjunto da paso a una nueva competencia geopolítica (Sanahuja, 2019b). Esos cambios ponen en cuestión la asociación birregional, al someter a fuertes tensiones internas a cada una de las partes y al sistema multilateral en el que se insertaban.

La creciente percepción de que la UE retrocede en América Latina, en el ámbito político y económico, no es ajena a esos a cambios estructurales en la economía política internacional. Esa percepción, aunque es parte de una narrativa interesada de bipolaridad entre China y Estados Unidos, responde a hechos materiales constatables. Uno de los indicadores más visibles es el fuerte avance de China como socio comercial y fuente de préstamos e inversiones. Entre 2000 y 2016 la cuota de mercado de China como proveedor de América Latina pasó del 3\% al 16\%, y la de la UE pasó del 16\% al 15\%, situándose por primera vez por detrás de China (Grieger, 2019). En Mercosur la UE ha perdido su tradicional primer lugar en las importaciones de este grupo, también en favor de China (Stratfor, 2018). Crece también el papel de China en la financiación del desarrollo, a través de préstamos (infraestructura, energía); como proveedor de financiación de contingencia ante crisis de balanza de pagos, permitiendo evitar el recurso al FMI (en Argentina o Venezuela); y en cuanto a la IED. La iniciativa de "Una Franja, Una Ruta" que impulsa Beijing también se percibe en esa clave geopolítica, en tanto desafío, aunque también puede suponer oportunidades para la UE en la región. 
La UE, por sus valores cosmopolitas, su propia construcción institucional y su inserción profunda en una economía globalizada, tiene mayores dificultades para responder a ese nuevo escenario de crisis de globalización y creciente competencia geopolítica. La debilidad o crisis de las organizaciones regionales y su actorness o condición de actor también erosiona la política europea, muy dependiente del interregionalismo si no se trata del diálogo bilateral con grandes potencias. En un escenario de fragmentación de Latinoamérica y el Caribe (crisis de las organizaciones regionales en América Latina, retirada o ausencia de Brasil o México como líderes regionales) y de mayor competencia geopolítica global, América Latina parece asumir que China y Estados Unidos, en plena guerra comercial y competencia tecnológica, son o serán los actores clave para el futuro económico de la región y/o para la gestión de las crisis regionales como la de Venezuela. A ello se suma la posición más asertiva de otros actores, como Rusia. Esa percepción de bipolaridad emergente, aunque cuestionable desde el punto de vista analítico y como narrativa de poder (Sanahuja, 2020c), debilita la posición e influencia de la UE en la región.

En ese escenario de crisis de globalización y contestación al orden liberal por parte de las nuevas fuerzas nacionalistas y de derecha radical, la integración regional y el regionalismo, así como el interregionalismo, se repolitizan y su racionalidad y sentido son cuestionados. Así lo ilustra es el anuncio de la firma del acuerdo UE-Mercosur en junio de 2019, en la cumbre del G20 en Osaka, que se convirtió en un acto de afirmación política y de principios frente al rampante nacionalismo económico del momento. Esa firma encierra una doble paradoja: siendo un acuerdo funcional a la globalización regionalizada de las décadas anteriores, y una tardía vindicación de la estrategia interregionalista de la asociación UE-América Latina, en realidad es impulsado por gobiernos que se ven cuestionados en casa por sus políticas neoliberales -Argentina en Mercosur, Francia en la UE-, hasta el punto de perder elecciones, en algunos casos, o estar en riesgo de perderlas con motivo de esas políticas. Por otro lado, se firma in extremis, ante el temor que suscitaba un escenario adverso de cuestionamiento de la integración regional y el multilateralismo, de creciente nacionalismo económico y proteccionismo comercial, de ausencia de árbitros y reglas en la economía política internacional, ante el inminente bloqueo de la Organización Mundial de Comercio (OMC) y, en suma, de globalización en retirada o en crisis (Sanahuja y Rodríguez, 2019).

El diálogo político también está en un momento difícil a causa, en primera instancia, de la fractura interna de CELAC causada por la crisis de Venezuela. La VIII Cumbre UE-CELAC, que debía celebrarse en 2017, se suspendió sine die, y el diálogo político región a región se realiza ahora con sordina, a nivel de cancilleres, y de manera bilateral o subregional, con ausencias y una agenda muy limitada. Pero hay otras tendencias de fondo que debilitan 
el diálogo político: más allá de la litúrgica -y poco efectiva- invocación a los principios y valores compartidos, las tendencias "iliberales" y las fracturas políticas en ambas regiones dificultan el consenso y la acción conjunta en torno a la democracia, los derechos humanos, el Estado de derecho y la cohesión e inclusión social. Son asuntos difíciles para ambas regiones, las sitúan frente a sus propias contradicciones y polarizan el debate -por ejemplo, en materia de migración-, por lo que tienden a evitarse.

Esas fracturas no han roto los amplios consensos eurolatinoamericanos existentes en muchos asuntos de la agenda global como el cambio climático, la Agenda 2030 de Desarrollo Sostenible, o la defensa del multilateralismo, pero no permiten forjar posiciones comunes en otras agendas de Naciones Unidas (derechos humanos, desarme y no proliferación) o en el G20, donde se actúa descoordinadamente -aunque tampoco conciertan Argentina, Brasil y México, los tres miembros de América Latina y el Caribe de este grupo-, lo que se suma al papel poco relevante que tiene en la actualidad esta plataforma de concertación.

Muchas delegaciones de la UE tienen dificultades para entablar un diálogo significativo sobre derechos humanos y democracia con los gobiernos y la sociedad civil, en un escenario, en muchos países, de retroceso de la democracia en América Latina y de estrechamiento de los espacios para las ONG (p. ej., en Nicaragua o en Brasil). Estas cuestiones han ido abriendo una brecha cada vez más grande entre políticas y prácticas, que afectan a la posición de ambas partes y su perfil normativo, basado en valores.

Puede alegarse que las fracturas internas en América Latina son un factor que explica ese alejamiento, pero parte de la explicación también radica en la UE. La EUGS de la UE de junio de 2016, ya mencionada, situó deliberadamente a América Latina en una posición periférica y poco relevante, al priorizar el "arco de inestabilidad" de la vecindad meridional y oriental de la UE (Mediterráneo, Balcanes, este de Europa). Planteó la relación con Latinoamérica en términos, primero, del apoyo a "órdenes regionales" para la gobernanza global; y, segundo, como estrategia para un Wider Atlantic, pero la elección de Trump, no prevista, situó a Estados Unidos como obstáculo más que como socio en las relaciones con Latinoamérica (Sanahuja, 2020a). Esa situación, sin embargo, ha tenido consecuencias positivas, al realzar el papel político de la UE como socio de América Latina y el Caribe en defensa del multilateralismo.

En materia de cooperación al desarrollo, la UE se encuentra frente a una región transformada: ya alberga muchos países con capacidad para enfrentar por sí mismos algunos de los retos del desarrollo y contribuir a las metas globales, pero, a la vez, tienen desafíos significativos que atender, en algunos casos históricos, como la desigualdad, y, en otros, generados por el entorno 
internacional más complejo que definen la globalización y sus transformaciones, que suponen nuevos factores de riesgo y vulnerabilidad. El ascenso de América Latina en los últimos años ha reducido las asimetrías entre ambas regiones y plantea retos compartidos, lo que demanda una relación más horizontal y hace más anacrónico el tono paternalista con el que algunos actores europeos siguen viendo a América Latina.

En su política de cooperación, la UE reconoció ese hecho, pero la respuesta fue inadecuada, por lo que se ha debilitado a sí misma como socio de Latinoamérica frente a actores como China en el desarrollo global, y regional, en el marco de la Agenda 2030. Para la cooperación de la UE, en el periodo presupuestario y de programación 2014-2020, América Latina no fue considerada prioritaria en tanto no era origen de flujos migratorios o fuente de inseguridad para la UE; y tampoco lo fue por sus mayores logros con los Objetivos del Milenio y sus relativamente más altos niveles de renta. En vez de buscar fórmulas más avanzadas e innovadoras de cooperación, la UE optó por retirarse parcialmente al "graduar" a la mayor parte de los países de América Latina por ser ya países de renta media o media-alta. Esa "graduación” se basó en indicadores simplistas y cuestionables, como la renta per cápita, y suponía la retirada de la ayuda bilateral y de determinadas preferencias comerciales. Ahora bien, si la Agenda 2030 es universal y no solo un asunto de países pobres parece poco coherente que la UE se incapacite a sí misma para cooperar con los países más avanzados de América Latina, logrando su apoyo en tanto actores clave para la búsqueda de soluciones a retos compartidos. Posteriormente, al evaluar los resultados de ese enfoque, la propia Comisión Europea reconoció que la "graduación" dejó una brecha en la capacidad de la UE para asociarse con países de renta media-alta mediante la cooperación bilateral. Tampoco se reconoció, hasta un momento muy tardío, el creciente papel de los países latinoamericanos como proveedores de cooperación Sur-Sur, o como partícipes de cooperación triangular (Sanahuja y Ruiz, 2020). La COVID-19, por último, ha demostrado de manera dramática que, a pesar de las asimetrías entre ambas regiones, hay retos comunes ante los que es imperativo trabajar juntos. Al convertirse pronto en una crisis de desarrollo global más que en una mera crisis sanitaria, la distinción entre graduados y no graduados, o entre Norte y Sur, es dañina e inadecuada. De hecho, a la hora de implementar programas de cooperación ante la pandemia, las normas legales y administrativas sobre la graduación que la UE se impuso a sí misma se han convertido en un obstáculo difícil de sortear para cooperar con varios países de la región.

Por ello, en vez de la "graduación", la UE debería encontrar formas de cooperación más innovadoras hacia la región. Así lo plantea el nuevo Consenso Europeo de Desarrollo, aprobado en 2017. Para muchos países de América Latina una cooperación con la UE más horizontal, basada en aprendizajes 
conjuntos y el diálogo sobre políticas, seguirá siendo relevante en muchas áreas de la acción pública, así como fuente de inversión, de transferencia de tecnologías y de fortalecimiento de capacidades. En la región también hay países que son socios de desarrollo importantes de la UE para lograr la Agenda 2030 a través de la cooperación Sur-Sur y triangular, y del trabajo conjunto en la provisión de bienes públicos regionales y globales, como muestra, de nuevo, la pandemia de la COVID-19.

Para ello, la cooperación con América Latina debería contar con suficientes recursos, y no parece que así sea en la propuesta de Marco Financiero Plurianual (MFP) 2021-2027. Dentro del MFP se ha propuesto un nuevo Instrumento para la Vecindad, el Desarrollo y la Cooperación Internacional (IVDCI). Frente al aumento para otras regiones o temáticas, la asignación para América Latina y el Caribe prevista en el IVDCI era ya la más baja de todas en la propuesta inicial, con una disminución del $12 \%$ en términos reales respecto al periodo anterior. Además, en el curso de la negociación del nuevo MFF y el programa de recuperación NEXT Generation EU, acordado el 21 de julio de 2020, se ha producido una reducción adicional, y los fondos totales para América Latina pueden pasar de los 4.000 millones de euros de la propuesta inicial a unos 3.000 millones. Hay que considerar, no obstante, que esos recursos serán accesibles para todos los países de América Latina, al margen de que estén o no graduados, a través del llamado Fondo Europeo de Desarrollo Sostenible (FEDS) plus, que puede suponer recursos significativos para apalancar fuentes de financiación adicional al objeto de impulsar, entre otras prioridades, infraestructuras sostenibles y la transición energética con energías renovables. Esta sería, a su vez, una expresión externa del European Green Deal y la transición energética que la UE pretende para ser neutral en carbono en 2050.

\section{Un escenario internacional en cambio: riesgos globales, pandemias y crisis del multilateralismo}

En 2016 la Unión Europea (UE) adoptó una nueva Estrategia Global y de Seguridad (EUGS). Este documento estableció como uno de sus principales objetivos la "resiliencia" social en un escenario internacional más complejo, disputado e interconectado. Lejos de las visiones confiadas y optimistas del pasado, la UE adoptaba una visión más circunspecta a su papel en el sistema internacional. Desde entonces se ha ido afirmando un escenario de crisis de la globalización, entendida esta como orden mundial hegemónico, y no solo como modelo económico. Ese escenario comporta nuevos desafíos, derivados de la erosión del orden liberal internacional, las estrategias revisionistas de potencias emergentes, y ascenso de fuerzas nacionalistas, iliberales y de 
extrema derecha, en particular en Estados Unidos o Brasil (Sanahuja, 2019). Todo ello debilita el sistema multilateral y la capacidad de gestionar o prevenir o mitigar los riesgos inherentes a una globalización muy profunda, pero sin gobernanza adecuada, como el cambio climático, las crisis financieras, los desplazamientos de población, y, como se ha planteado en 2020, pandemias como la de la COVID-19. En aras de una mayor resiliencia, la EUGS reconocía el vínculo interno-externo de la seguridad, y proponía fortalecer la capacidad de cada país, por sí solo y a través de la cooperación internacional, para encajar y sobreponerse a un choque externo derivado de esos riesgos. Ese era un objetivo que interpelaba a una UE que se sabía vulnerable ante esos riesgos, pero también era un eje, como se indicó, de las relaciones exteriores y de la cooperación con los países en desarrollo, menos resilientes, especialmente en su entorno geográfico más cercano (Sanahuja, 2020a).

La pandemia de la COVID-19 de 2020 muestra cuán relevantes eran esos riesgos, y supone también una prueba decisiva de resiliencia para las sociedades, las economías y la gobernanza en todo el mundo. La propia UE ha sufrido un golpe sin precedentes, con los sistemas de salud de algunos países al límite, aprendiendo sobre la marcha cómo "aplanar la curva" del contagio, y buscando nuevos acuerdos monetarios y fiscales para sostener su economía y sus servicios públicos. A través de negociaciones agónicas en el Eurogrupo y el Consejo, que evocan las que jalonaron la crisis del euro a inicios de la década anterior, ha tenido que buscar una respuesta mancomunada a una crisis que es, al tiempo, sanitaria, económica, social y de gobernanza. La crisis ha hecho emerger y ha agravado patrones de desigualdad entre personas y países que ya existían, así como debilidades institucionales previas a la crisis: sistemas de salud desiguales y, en algunos casos, debilitados por los recortes posteriores a la gran recesión de 2008; menor margen fiscal y de políticas para preservar, simultáneamente, la salud y la actividad económica, el empleo y los medios de vida, en una unión monetaria aún incompleta y con serios problemas de diseño; tendencias preocupantes en cuanto a desafección democrática, y la influencia de la extrema derecha, que han debilitado la capacidad de responder colectivamente y evitar el "nacionalismo epidemiológico" que conduce al cierre de fronteras o a restricciones al comercio. En ese contexto, el acuerdo del Consejo Europeo de 21 de julio de 2020 tiene una extraordinaria trascendencia, aún más ante los datos aparecidos a finales de ese mes, que muestran un desplome de la actividad económica que ya es el más grave desde mediados del siglo XX.

América Latina, por su parte, ya iniciaba el año 2020 con la economía estancada y un entorno adverso. Desde el fin del ciclo de las materias primas en 2014, las tasas de crecimiento eran las más bajas de las últimas siete décadas, el empleo y el bienestar retrocedían, y aumentaba la pobreza. En 
el plano político, más allá de los retrocesos de la democracia en Venezuela o Nicaragua, existía en toda la región un amplio "malestar en la democracia", con crisis de representación, desafección y bajos niveles de confianza. En 2019 se registraron los peores índices de satisfacción con el funcionamiento de la democracia de los últimos veinte años (Corporación Latinobarómetro, 2018), y en el "súper ciclo" electoral de 2017 a 2019, con elecciones legislativas y/o presidenciales en todos los países, el único patrón claro fue el reclamo de cambio y la derrota del oficialismo, al margen del clivaje izquierda-derecha (Zovatto, 2020). Aunque hay factores nacionales muy diversos, estos elementos son comunes a las crisis políticas de la región, sea el ascenso de la ultraderecha (Brasil, Bolivia) o las revueltas sociales de países como Chile o Colombia. La desigualdad y las diferencias de acceso - por nivel de renta, género o etniaseguían siendo enormes, y la región, con el epicentro en Venezuela, enfrentaba la peor crisis migratoria de su historia reciente. América Latina, por último, también había perdido capacidad de cooperar y actuar colectivamente en el plano regional y global, al haber desmantelado parte de sus organizaciones regionales por iniciativa de los gobiernos de derecha de la región a causa de la polarización y la fragmentación política. La región, más fragmentada y sin lograr tener voz propia, es percibida como una arena de competencia creciente de Estados Unidos y China (Sanahuja, 2019a).

Con todas esas condiciones de partida el desafío para América Latina también es titánico. Las medidas drásticas de confinamiento y distancia física frente al contagio lograron retrasar en algunos países el ascenso de la curva de contagio, pero en otros no han sido efectivas ante unas condiciones sociales y sanitarias que hacían difícil que esas medidas fueran efectivas. A ello se suman países que actuaron de manera titubeante, o abiertamente negligente. Como resultado, a mediados de junio de 2020 la región, con solo el $8 \%$ de la población mundial, se había convertido en el epicentro mundial de la pandemia, con la mitad de los fallecimientos según el promedio móvil de siete días. Y lo que comenzó como una crisis sanitaria se ha convertido en una crisis de desarrollo mucho más amplia. Un factor clave es la desigualdad: en el empleo, la renta, el cuidado y el acceso a servicios de salud. Al ser parte de titularidad privada, no existe acceso igualitario a las pruebas y a la atención médica de calidad. Pero los efectos más lacerantes de la desigualdad se plantean en las medidas de prevención y contención del contagio. Para quienes residen en viviendas inadecuadas, en favelas o villas, o tienen que utilizar el metro o microbuses atestados, aislarse para prevenir el contagio no es una opción. Quienes viven al día, con ingresos muy bajos o en el sector informal, no pueden permitirse el confinamiento y la inactividad laboral durante semanas o meses. Los migrantes quedan en un limbo laboral y legal que impide sobrevivir. 
Según proyecciones de Naciones Unidas (CEPAL, 2020), la región registrará en 2020 una caída del PIB de $-9,1 \%$, la peor de su historia, y no tiene apenas espacio fiscal y de política para incrementar el gasto en salud, asegurar una renta mínima a quienes son pobres o vulnerables, o sostener a las empresas, especialmente las pymes, para que puedan recuperarse tras la pandemia. Estados Unidos puede recurrir a la Reserva Federal y financiarse en su propia moneda. En la UE el Banco Central Europeo puede ampliar las opciones de financiación, y se puede recurrir a los créditos de contingencia del Mecanismo Europeo de Estabilidad y, quizás, a mutualizar deuda o financiar un gran fondo de recuperación. Salvo el recurso al Fondo Monetario Internacional (FMI), que supone un injusto estigma financiero y no tiene los recursos para responder a una crisis como esta, nada similar existe en Latinoamérica y el Caribe. Sin respuestas adecuadas, además del elevado coste humano, en ese desplome económico también radican serios riesgos políticos en la región ante el ascenso de fuerzas de ultraderecha.

Siendo una pandemia global, nadie está a salvo, menos aún con respuestas exclusivamente nacionales. Frente a brotes infecciosos, la salud es buena medida un bien público. Asegurar la provisión de bienes públicos regionales y globales -y evitar males públicos como la pandemia del coronavirus- exige una cooperación internacional robusta para asegurar que se actúe concertadamente y entre todos evitemos que haya "eslabones débiles" allí donde hay Estados con menos capacidad o recursos. Sin duda, hay distintas capacidades y responsabilidades de partida, pero sin cooperación y apoyo mutuo su impacto puede ser aún más devastador para todos. Esta crisis obliga a recordar que la resiliencia social depende también de la cooperación internacional.

Esta crisis exige, en suma, un nuevo esfuerzo de cooperación internacional, y es el marco obligado en el que se sitúan las relaciones entre la UE y América Latina y el Caribe.

\section{Bases para la renovación de la política de la UE hacia América Latina}

Desde 2009 no se había revisado la política de la UE con América Latina hasta que, en abril de 2019, se adopta una nueva estrategia hacia la región en el marco de la EUGS. Para ello se elaboró, por primera vez, una Comunicación Conjunta de la Comisión Europea, el Servicio Europeo de Acción Exterior (SEAE), y la Alta Representante para la Política Exterior y de Seguridad de la Unión Europea y vicepresidenta de la Comisión Europea, en ese momento Federica Mogherini (Comisión Europea, 2019). Se trata de un planteamiento renovado tanto en el análisis del contexto, como en los objetivos y las estrategias de acción. Horizontalidad, repolitización, enfoque selectivo y nuevas prioridades 
de cooperación son los términos que resumen las principales novedades planteadas ${ }^{2}$. Como señala textualmente dicho documento en su sección final,

La UE cree que la asociación debería adoptar una postura más fuerte respecto a los valores e intereses vitales - prosperidad, democracia, resiliencia y gobernanza mundial efectiva- y hacer un uso mejor y más específico de las diferentes dimensiones de las relaciones UE-América Latina y el Caribe. La UE trabajará para lograr un compromiso político más estratégico, intensificando los esfuerzos de asociación con los países o grupos regionales dispuestos a hacer más para alcanzar objetivos comunes.

Se aboga, en primer lugar, por una relación más horizontal: habla de "aunar fuerzas" para abordar desafíos compartidos como la defensa del multilateralismo, o el desarrollo global, entendido -como lo hace la Agenda 2030 - como reto universal y no solo como "patología" de los países pobres. No se trata, como en el pasado, de una UE que ayuda a América Latina a resolver sus problemas, sino de dos regiones que trabajan juntas frente a interdependencias, riesgos y retos compartidos.

También se asume una repolitización de las relaciones al proponer un "compromiso político más estratégico" ante un escenario en el que la democracia y los principios que sostienen el orden internacional liberal ya no pueden darse por sentados, y en el que aparecen actores que los impugnan dentro y fuera de ambas regiones. Se plantea, por ello, una clara repolitización del conjunto de la relación y, en particular, de un diálogo político birregional que debe recuperarse y extenderse a áreas hasta ahora solo abordadas en el plano de la cooperación técnica, como la cohesión social. Ello supondrá adoptar posturas "más fuertes" en torno a los valores e intereses compartidos. Por parte de la UE se requiere una mayor inversión de capital político para ser relevante como interlocutor, y aumentar la presencia e influencia en la región basándose en el "pragmatismo basado en principios" de la EUGS.

En línea con la EUGS se proponen cuatro nuevas prioridades para la asociación birregional: prosperidad, democracia, resiliencia y gobernanza mundial efectiva. Ello abarca una agenda de cooperación avanzada para facilitar el comercio, la economía verde y digital y aumentar la conectividad de todo tipo. Se mantiene la atención a los derechos humanos, el apoyo a la sociedad civil y la defensa del Estado de derecho, hoy más cuestionados que en etapas anteriores. En términos de resiliencia se aspira a la implementación conjunta del Acuerdo de París para enfrentar el cambio climático. En cuanto a la gobernanza mundial efectiva, se busca que tanto la UE como América Latina apuesten conjuntamente por la resolución

\footnotetext{
2 Algunas de estas ideas ya habían sido recogidas en un informe elaborado algunos años antes por iniciativa de la Fundación EU-LAC (Sanahuja, 2015).
} 
pacífica de disputas, la implementación de la Agenda 2030 y la reforma de Naciones Unidas y la OMC.

Para reactivar el diálogo político y la cooperación se propone una relación de "geometría variable" con vías más flexibles y abiertas de colaboración respecto a la tradicional dinámica de las cumbres birregionales UE-CELAC y su lógica de "mínimo común denominador", que a partir de la regla del consenso exigía el acuerdo de todos. Asimismo, evita el enfoque de "talla única" reconociendo la diversidad de América Latina y el Caribe. Supone avanzar más con los países y grupos que quieran y puedan intensificar su compromiso.

Esa "repolitización", unida a la posibilidad de establecer agrupamientos de geometría variable, es particularmente relevante ante las crisis de difícil resolución que experimenta la región (Venezuela, Nicaragua, retrocesos en el proceso de paz colombiano, crisis ecológica en la Amazonia...). Estas crisis multidimensionales no parecen tener solución ni en los mecanismos regionales como la Organización de los Estados Americanos (OEA), ni en los agrupamientos ad hoc como el Grupo de Lima, además de tener severas consecuencias para los países vecinos. En ese sentido, la UE habría de jugar un papel político más activo asociándose con los países y los actores sociales más dispuestos. En otros términos, supondría combinar el interregionalismo con un bilateralismo selectivo y no excluyente, utilizando marcos existentes u otros informales, como el Grupo de Contacto Internacional (GCI) establecido para afrontar la crisis de Venezuela. A ello han de sumarse los espacios de diálogo y vinculación de organizaciones ciudadanas y de parlamentarios.

Para la cooperación al desarrollo se propone una estrategia avanzada, conforme al nuevo Consenso Europeo de Desarrollo, con enfoques "a medida" para cada país, basados en sus necesidades y capacidades, buscando "asociaciones innovadoras" que contemplen la cooperación Sur-Sur y triangular, el diálogo de políticas públicas, el intercambio de conocimientos, $\mathrm{y}$ la movilización de recursos adicionales a través de la financiación combinada o blending. Se trata de una aproximación más simétrica y horizontal, y, por ello, más coherente con la Agenda 2030. Esta última plantea una visión de la cooperación más amplia e inclusiva, que no ha de dejar a nadie atrás, superando los esquemas dicotómicos rico/pobre, Norte/Sur o donante/ receptor, aún arraigados en la cooperación y las relaciones internacionales. Esquemas, como se indicó, basados en indicadores tan cuestionables como la renta per cápita como criterio casi único o más relevante para definir el desarrollo y clasificar países.

En realidad, los umbrales que definen qué es "renta media" o "renta alta" dicen bastante poco sobre la amplia variedad de situaciones de transición al desarrollo que atraviesan los países situados entre esos umbrales de ingreso, en especial en América Latina y el Caribe. El desarrollo debiera verse como 
un proceso continuado con situaciones muy diversas, en función de las metas de la Agenda 2030, más que como una cuestión de categorías cerradas y unidimensionales basadas en niveles de renta. Desde la perspectiva de la Agenda 2030, América Latina y el Caribe, en particular, puede ser vista como una región de "desarrollo en transición” (OCDE/CEPAL, 2019).

Por ello, más que de "graduación" debiera hablarse de "gradación", incorporando una batería más completa, compleja y diversa de indicadores de inclusión, sostenibilidad ambiental y buena gobernanza tomados de la Agenda 2030 y los Objetivos de Desarrollo Sostenible (ODS), en el entendido de que la exclusiva alusión a mayores ingresos no supone más bienestar. Ante el futuro inmediato, acaso lo más urgente consista en alcanzar un consenso eurolatinoamericano sobre el significado concreto del "desarrollo en transición" y la comprensión de las "trampas" del desarrollo que afectan a la región para hacer realidad la Agenda 2030, en cuanto a los indicadores y métricas a aplicar y respecto a las modalidades de cooperación.

En particular, el nuevo IVDCI abre oportunidades para el despliegue de esa cooperación avanzada y para ideas innovadoras. Deja atrás la "graduación" y estará abierto a todos los países de la región, aunque no en todas las modalidades. Como se indicó, prevé montos importantes para el blending y el apoyo a la inversión, que refuerzan la capacidad de la UE frente a actores activos en ese ámbito, como China.

Una vez aprobado el nuevo instrumento, los nuevos programas regionales y temáticos deberán permitir que la UE pueda atender a la diversidad de agendas de desarrollo que plantea la particular situación de transición de América Latina y el Caribe. Es importante que el nuevo instrumento tenga un claro anclaje y orientación hacia la Agenda 2030. El ciclo de programación ha empezado en 2020; es el momento de incluir iniciativas innovadoras y programas relevantes para las prioridades de desarrollo de la región. Con esos elementos, el "desarrollo en transición", como concepto impulsor de nuevas formas de cooperación internacional para el desarrollo, puede servir para replantear y fortalecer las relaciones entre la UE y América Latina y el Caribe, con el fin de que ambas regiones puedan contribuir de una manera efectiva al cumplimiento de la Agenda 2030 y los ODS.

\section{Frente a la COVID-19: una "UE geopolítica" con una agenda de prioridades sociales}

Ante el escenario regional y global de erosión del multilateralismo, competencia geopolítica y crisis de globalización, acelerada por la crisis de la COVID-19, ¿cómo puede actuar la UE en América Latina y el Caribe 
con la visión geopolítica que la nueva Comisión Von der Leyen asume como orientación estratégica y seña de identidad de su mandato? ¿Debe dejar atrás su perfil de "actor normativo" y los principios que presiden su política exterior, "aprender a utilizar el lenguaje del poder", como lo ha expresado el Alto Representante, Josep Borrell (2019: 7), y competir con otros actores como Estados Unidos o China en la lógica de la política de poder y la competencia geopolítica?

Pese a las limitaciones de la construcción intergubernamental de su política exterior y de seguridad común (PESC), la UE cuenta, en efecto, con importantes recursos de poder en su política comercial y de desarrollo, y en otros ámbitos, en términos de incentivos y sanciones; con un importante ascendiente simbólico y normativo, basado justamente en su apego a los principios contemplados en los tratados y en su tradición política; y con medios significativos, que abarcan desde un servicio diplomático propio a los que contempla el presupuesto para la acción exterior. Actor sui generis de las relaciones internacionales, como siempre se ha dicho, pero, sin duda, actor, y con una capacidad de agencia notable. Por último, a esos recursos propios se suma la capacidad de coordinar la acción exterior de los Estados miembros en el marco común de la Unión.

En este contexto, la vinculación de objetivos y medios en distintas áreas de acción (linkage), en una lógica más "repolitizada", puede ser una vía eficaz para promover tanto intereses como principios. No se trata -es importante subrayarlo- de imponer unilateralmente agendas propias de la UE, sino de establecer coaliciones efectivas con los gobiernos y los actores relevantes para que las relaciones birregionales permitan avanzar intereses y valores comunes frente a quienes, desde posiciones iliberales y ultranacionalistas, tratan de impugnarlos. Actores -también es oportuno recordarlo- que están presentes en ambas regiones. Cuestiones como la preservación de la biosfera o la reconstrucción del contrato social son problemáticas comunes, y para ello tiene sentido actuar conjuntamente. Un ejemplo de ello sería la vinculación del Acuerdo UE-Mercosur al Acuerdo de París sobre cambio climático, que ha actuado como elemento de contención ante un eventual abandono de ese acuerdo por parte del Brasil de Bolsonaro y ha incrementado el coste de su política lesiva para el medio ambiente. Otro caso es el tradicional rechazo birregional de las sanciones extraterritoriales estadounidenses de la Ley Helms-Burton. En 2017 la Administración Trump decide aplicar plenamente esta ley, hasta ese momento parcialmente en suspenso. En respuesta, entre otras acciones políticas y legales, la UE actualizó su "Estatuto de bloqueo", que permite que los afectados por la Ley Helms-Burton puedan iniciar acciones legales en territorio de la UE contra empresas estadounidenses demandantes de sanciones. 
En esa lógica, la UE puede ser más activa dando respaldo y acompañamiento político a los actores que, desde la propia región, promueven salidas negociadas y pacíficas a las crisis regionales. De esa manera se contribuye a crear el necesario espacio para maniobrar para dichos actores frente a la lógica geopolítica y de equilibrios de poder que guían las intervenciones en la región, cada vez más directas, de Estados Unidos, China o Rusia. Cuando sea necesario, la UE ha de seguir actuando con un perfil propio e iniciativas singulares frente a esas crisis. Un caso evidente es Venezuela. Ante el riesgo de enquistamiento de esa crisis, es necesario hacer frente a su dimensión política, apoyando una salida negociada y promoviendo elecciones con garantías democráticas, así como a la dimensión humanitaria, con iniciativas que permitan utilizar los recursos petroleros del país para adquirir bienes esenciales en el exterior. Ello podría lograrse mediante una suspensión parcial de las sanciones estadounidenses, como propone la iniciativa denominada "Petróleo para Venezuela", que es particularmente relevante ante el imperativo de salud de la COVID-19.

Más allá de estos escenarios de crisis, en América Latina y el Caribe una "UE geopolítica" ha de estar basada en una agenda social, más que en equilibrios de poder. La UE es ahora el único actor global que en la geopolítica regional se aproxima a Latinoamérica con una agenda centrada en las preocupaciones centrales de sus sociedades: la inclusión, la calidad de la democracia, los derechos humanos, la igualdad de género, la paz, la justicia y la seguridad ciudadana. En suma, con todo aquello que integra la Agenda 2030, cuyos contenidos pueden ser vistos como una renovación del "contrato social", que hoy está en cuestión y ha de ser reconstruido tanto en la UE como en Latinoamérica. En particular, América Latina y el Caribe ofrece una oportunidad para que el European Green Deal o "pacto verde europeo" de la UE, lanzado en 2020 por la Comisión von der Leyen, desarrolle su dimensión externa. Para todo ello, urge retomar el diálogo político birregional y promover una política de cooperación más activa e innovadora a través de los nuevos programas e instrumentos financieros que se están definiendo dentro del MFF 2021-2027.

La crisis de la COVID-19, por último, plantea imperativos inmediatos en esa agenda a la vez social y geopolítica. La UE y sus Estados miembros están ya prestando apoyo en el ámbito sanitario, y a través de la propuesta de la Comisión "Equipo Europa" se ha decidido reorientar de inmediato los programas de cooperación técnica y financiera con América Latina y el Caribe para responder a esta pandemia, con los fondos disponibles de la Comisión Europea y las líneas de crédito del Banco Europeo de Inversiones. Esos recursos, en cualquier caso, son limitados frente a la magnitud de la crisis sanitaria y del colapso económico y social que la COVID-19 puede traer consigo. Por ello, la asociación estratégica entre la UE y Latinoamérica y el Caribe puede ser más efectiva a través de una respuesta multilateral robusta. 
Aquellos países de la UE y de América Latina y el Caribe que estén dispuestos han de trabajar con una perspectiva común en el G20 y en las instituciones financieras multilaterales para que exista más espacio fiscal a fin de evitar el colapso sanitario, el desplome económico y una grave crisis social y, quizás, política. Ello dependerá en gran medida del acceso urgente a la financiación externa. Si está ausente, algunos actores externos pueden ver en esta situación, de manera oportunista, una vía para utilizar la asistencia bilateral con objetivos geopolíticos, como es el caso de China con su "diplomacia de mascarilla". En el ámbito interno, la falta de respuesta en sociedades fragmentadas por la desigualdad y la desconfianza política puede ser terreno abonado para partidos de extrema derecha, ultranacionalistas, con discursos nativistas y xenófobos, que minarían aún más la necesaria cooperación internacional.

De momento, las respuestas multilaterales no han sido adecuadas ni ágiles. El FMI y el Banco Mundial ya han anunciado líneas de financiación y alivio de la deuda de los países más pobres, pero no deben olvidarse los países de renta media lastrados por un alto endeudamiento en América Latina. Hay precedentes: en la crisis de 2008, el G20 actuó con resolución y, a instancias de ese foro, el FMI multiplicó por cuatro su capital. Hoy las necesidades son mayores y se deben considerar todas las opciones existentes para movilizar más recursos, como por ejemplo la aprobación de una nueva emisión extraordinaria de derechos especiales de giro, la reserva del FMI, que se distribuya de manera que refuerce en mayor medida las reservas de los países más necesitados, si bien Estados Unidos, con capacidad de veto en el FMI, ha bloqueado esta opción.

En ese marco, como se indicó, tampoco es el momento de las sanciones económicas generalizadas, que ya antes de la pandemia tenían un grave coste humano, y vedan el acceso a recursos externos que son vitales para la respuesta sanitaria y la protección de los más vulnerables. Y debe promoverse una respuesta conjunta para evitar la instrumentalización, por parte de la administración Trump, de instituciones clave en la región, como es el caso del Banco Interamericano de Desarrollo.

Ante lo que ya se anuncia como la mayor crisis económica y social -y, quizás, política- de la historia reciente, hay que recordar de nuevo que la resiliencia social depende también de la cooperación internacional. Y que esa cooperación será clave para que la crisis de la COVID-19 sea una oportunidad para reescribir el contrato social que ha de reescribirse en ambas regiones. La UE y América Latina y el Caribe - una asociación con nada menos que 61 países- tienen, por ello, el imperativo de aunar esfuerzos de nuevo, y la oportunidad de mostrar la utilidad de sus vínculos. 


\section{Referencias bibliográficas:}

Borrell, J. (2019): "La política exterior de la Unión Europea en tiempos desafiantes", Documentos de Trabajo nº especial, Fundación Carolina, octubre.

CEPAL (2020): "Enfrentar los efectos cada vez mayores del COVID-19 para una reactivación con igualdad: nuevas proyecciones", Informe Especial COVID-19 $\mathrm{n}^{\mathrm{0}}$ 5, Santiago de Chile, Comisión Económica para América Latina y el Caribe (CEPAL), 15 de julio, S2.000471.

Comisión Europea/Alta Representante de la Unión Europea para Asuntos Exteriores y Política de Seguridad (2019): Comunicación Conjunta al Parlamento Europeo y al Consejo. La Unión Europea, América Latina y el Caribe: aunar fuerzas para un futuro común, Bruselas, JOINT (2019) 6 final (16 de abril).

Coorporación Latinobarómetro (2018): Informe 2018. Santiago de Chile: Corporación Latinobarómetro.

Domínguez, R. (2015): EU Foreign Policy Towards Latin America, Londres, Palgrave Macmillan.

Domínguez, R. (2020): "La resiliencia en la modernización del Acuerdo Global UE-México", Análisis Carolina 45/2020, 27 de julio.

Grieger, G. (2019): EU Trade with Latin America and the Caribbean. Overview and Figures, Bruselas, European Parliamentary Research Service, PE 644.219, diciembre.

OCDE/CEPAL (2019): Perspectivas económicas de América Latina 2019: Desarrollo en transición, París, OECD.

Sanahuja, J. A. (2015): La UE y CELAC: revitalización de una relación estratégica, Hamburgo, Fundación EU-LAC.

Sanahuja, J. A. (2019a) "La crisis de la integración y el regionalismo en América Latina: giro liberal-conservador y contestación normativa", en Mesa, M. (Coord.) Ascenso del nacionalismo y el autoritarismo en el sistema internacional. Anuario 2018-2019, Madrid: CEIPAZ, pp. 107-127.

Sanahuja, J. A. (2019b): "Crisis de la globalización, el regionalismo y el orden internacional liberal: el ascenso mundial del nacionalismo y la extrema derecha", Revista Uruguaya de Ciencia Política vol. 28, n 1, pp. 59-94.

Sanahuja, J. A. (2020a): "The EU Global Strategy: Security, Narratives, Legitimacy and Identity of an Actor in Crisis", en Conde, E., Yaneva, Z., y Scopelliti, M. (eds.), The Routledge Handbook of European Security Law and Policy, Londres, Routledge, pp. 395-414. 
Sanahuja, J. A. (2020b): “COVID-19: Riesgo, pandemia y crisis de gobernanza global”, en Mesa, M. (Coord.), Riesgos globales y multilateralismo: el impacto de la COVID-19. Anuario CEIPAZ 2019-20, Madrid, CEIPAZ, pp. 27-54.

Sanahuja, J. A. (2020c): “¿Bipolaridad en ascenso? Análisis equívocos frente a la crisis de la globalización”, Foreign Affairs Latinoamérica vol. 20, n² abril-junio, pp. 76-84.

Sanahuja, J. A. y Rodríguez, J. D. (2019): "Veinte años de negociaciones UE-Mercosur: del interregionalismo a la crisis de la globalización", Documentos de trabajo $\mathrm{n}^{\circ} 8 / 2019$, Fundacion Carolina, septiembre.

Sanahuja, J. A. y Ruiz, E. (2020): “La Unión Europea y la Agenda 2030 en América Latina: políticas de cooperación en una región de desarrollo en transición” en Sanahuja, J. A. (ed.), La Agenda 2030 e Iberoamérica. Politicas de cooperación y “desarrollo en transición”, Madrid, Fundación Carolina, pp. 297-360.

Sojo, A. (2020): “Pandemia o Pandemónium: Encrucijadas de la salud pública latinoamericana en un mundo global", Fundación Carolina, Documentos de Trabajo 37/2020.

Stratfor (2018): "Brazil's Next President Is Looking to Shake Up Mercosur", 30 de noviembre.

Tvevad, J. (2020): The EU and Latin America and the Caribbean: towards a stronger partnership?, Bruselas, European Parliament, Policy Department for External Relations PE 639.314, enero.

Unión Europea (2016): Una visión común, una actuación conjunta: una Europa más fuerte. Estrategia global para la política exterior y de seguridad de la Unión Europea, Bruselas, Servicio Europeo de Acción Exterior (SEAE), junio.

Zovatto, D. (2020): “El súper ciclo electoral latinoamericano 2017-2019: el voto de enojo en tiempos de fatiga democrática y malestar con la política”, Análisis Carolina 03/2020, 23 de enero. 
